\title{
Article \\ Design and Synthesis of Multi-Functional Superparamagnetic Core-Gold Shell Nanoparticles Coated with Chitosan and Folate for Targeted Antitumor Therapy
}

\author{
Sharafaldin Al-Musawi ${ }^{1, *}$, Salim Albukhaty ${ }^{2}{ }^{(}$, , Hassan Al-Karagoly ${ }^{3}\left(\mathbb{D}\right.$ and Faizah Almalki ${ }^{4}(\mathbb{C}$ \\ 1 Faculty of Biotechnology, Al-Qasim Green University, Babylon 51013, Iraq \\ 2 Department of Chemistry, College of Science, University of Misan, Maysan 62001, Iraq; \\ albukhaty.salim@uomisan.edu.iq \\ 3 Department of Internal and Preventive Medicine, Veterinary Medicine College, University of Al-Qadisiyah, \\ Al-Diwaniyah 58002, Iraq; hassan.aliwee@qu.edu.iq \\ 4 Faculty of Science, Taif University, Taif 21944, Saudi Arabia; fa.ahmad@tu.edu.sa \\ * Correspondence: dr.sharaf@biotech.uoqasim.edu.iq
}

check for

updates

Citation: Al-Musawi, S.; Albukhaty, S.; Al-Karagoly, H.; Almalki, F. Design and Synthesis of

Multi-Functional Superparamagnetic Core-Gold Shell Nanoparticles Coated with Chitosan and Folate for Targeted Antitumor Therapy. Nanomaterials 2021, 11, 32.

http:/ /dx.doi.org/10.3390/ nano11010032

Received: 21 November 2020 Accepted: 19 December 2020 Published: 24 December 2020

Publisher's Note: MDPI stays neutral with regard to jurisdictional claims in published maps and institutional affiliations.

Copyright: $\odot 2020$ by the authors. Licensee MDPI, Basel, Switzerland. This article is an open access article distributed under the terms and conditions of the Creative Commons Attribution (CC BY) license (https: / / creativecommons.org/ licenses/by/4.0/).

\begin{abstract}
A dual-targeting nanomedicine composed of $\mathrm{pH}$-sensitive superparamagnetic iron oxide core-gold shell SPION@Au, chitosan (CS), and folate (FA) was developed as a doxorubicin (DOX) antitumor medication. Microemulsion was used for preparation and cross-linking conjugation. The characteristics of the designed nanocomposite were studied using atomic force microscopy (AFM), transmission electron microscopy (TEM), scanning electron microscopy (SEM), X-ray diffraction, UV-visible spectroscopy, Zeta potential and vibrating sample magnetometry (VSM), and Fourier transform infrared spectroscopy. The prepared SPION@Au-CS-DOX-FA nanoparticles (NPs) were spherical with an average diameter of $102.6 \pm 7 \mathrm{~nm}$ and displayed an elevated drug loading behavior and sustained drug release capacity. The SPION@Au-CS-DOX-FA NPs revealed long term anti-cancer efficacy due to their cytotoxic effect and apoptotic inducing efficiency in SkBr3 cell lines. Additionally, Real-time PCR outcomes significantly showed an increase in BAK and BAX expression and a decrease in BCL-XL and BCL-2. In vivo results revealed that SPION@Au significantly decreased the tumor size in treated mice through magnetization. In conclusion, prepared SPION@Au-CS-DOX-FA could be a beneficial drug formulation for clinical breast cancer treatment.
\end{abstract}

Keywords: superparamagnetic iron oxide nanoparticles; gold nanoparticles; doxorubicin; chitosan; breast cancer; folate

\section{Introduction}

Breast cancer is a major recurring cause of death for women worldwide; hence, the development of modern diagnostic methods for breast cancer in the early stages is essential for the possible treatment of this disease [1,2]. Conventional treatment methods generally include surgery, chemotherapy, and radiotherapy to eradicate tumors. Most chemotherapy agents have a systemic effect, are insufficiently targeted, and poorly penetrate the intended treatment site [3]. Doxorubicin (DOX) is one of the most efficient anti-cancer substances and is extensively used to treat breast cancer and other malignancies such as bladder, ovarian, and lung cancer $[4,5]$. However, its clinical use is limited due to its dose-dependent cell toxicity (myelosuppression and cardiotoxicity), multidrug resistance development, and low specificity against cancer cells [6,7]. Current research progress on nanotechnology has led to the development of nanocarrier-drug delivery vehicles and their potential applications in gene delivery and cancer therapy [8-10]. Superparamagnetic nanoparticles (NPs) (SPIONs) have emerged as a superior agent in tumor therapy because of their unique properties, particularly the superior magnetism that permits non-invasive magnetic resonance imaging (MRI) and in vivo applications such as cancer tissue hyperthermia by a targeted technique in the presence of an external magnetic field [11-15]. This field promotes the cellular 
uptake of NPs containing magnetic materials. The combination of Au NPs and SPION enables drug accumulation in a specific location in the body by using a magnetic field for effective targeted therapy at the tumor site [16]. The Au-coated SPION is a robust platform and a suitable agent for improving stability, biocompatibility, and surface interaction [17]. The chitosan (CS) surface is a natural cationic polysaccharide that exhibits low toxicity, biocompatibility, and hydrophilicity and is subsequently considered for DOX delivery [18]. This surface has been widely used for the dispersion of SPIONs in an aqueous solution. Folate (FA) receptor is highly overexpressed on many surfaces of cancer cell lines [19]. FA-coated SPION NPs exhibit significant cellular uptake improvement compared with unmodified NPs [20]. This study aimed to develop a multifunctional nanoparticle composed of biocompatible factors (SPION, Au, CS, and FA) and analyze its ability to reduce DOX toxicity and its applicability for targeted cancer cell therapy. In addition, the therapeutic effects were assessed on in vitro and in vivo animal model tumor cancer cells.

\section{Materials and Methods}

\subsection{Chemical Materials}

Ferric chloride, hexahydrate $\left(\mathrm{FeCl}_{3} \cdot 6 \mathrm{H}_{2} \mathrm{O} \geq 99 \%\right)$, and ferrous chloride tetrahydrate $\left(\mathrm{FeCl}_{2} \cdot 4 \mathrm{H}_{2} \mathrm{O} \geq 99 \%\right.$ ), strong Ammonium hydroxide solution (99\%) 25\% (v/v), 3-(4,5dimethyl-2-thiazolyl)-2,5-diphenyl-2H-tetrazolium bromide (MTT), and dimethyl sulfoxide (DMSO) ( $\geq 99.8 \%$ ) were purchased from Merck (Merck, Germany). SkBr3 and MCF 10A cell lines were acquired from ATCC (Manassa, CO, USA). DMEM medium and other factors were obtained from Gibco (Gibco, UK).

\subsection{Preparation of SPIONs}

SPIONs were prepared and optimized through chemical co-precipitation [21].

Synthesis of SPION@Au Core-Shell and SPION@Au-CS-DOX-FA NPs

SPION@Au was fabricated following a previous procedure [22] with slight modifications. In brief, $12.5 \mathrm{~g}$ of SPIONs were dispersed in a beaker with a flat bottom containing $250 \mathrm{~mL}$ of distilled water and $0.1 \mathrm{M} \mathrm{HAuCl}_{4}(\geq 99.9 \%) \cdot 4 \mathrm{H}_{2} \mathrm{O}$ mixture for $15 \mathrm{~min}$. The mixture was ultrasonicated a beaker with a flat bottom for $15 \mathrm{~min}$, and incubated at $38^{\circ} \mathrm{C}$ for easy Au3+ adsorption into SPION surface. The excess gold ions are typically extracted by centrifugation for $30 \mathrm{~min}$ at $(10,000 \mathrm{RCF})$. Then, the clear supernatants were included in practical use. Glucose $(1 \mathrm{mg} / 5 \mathrm{~mL})$ was used as a reducing factor in the mixture, which was shaken and incubated at room temperature. The formed SPION@Au composite was then cleaned with distilled water several times until the $\mathrm{pH}$ scale reached 7 and was analyzed by atomic force microscopy (AFM, OMCL-RC800PSA-1, Olympus, Tokyo, Japan), scanning electron microscopy (SEM, Carl Zeiss, Supra 55, Oberkochen, Germany), transmission electron microscopy (TEM, Carl Zeiss, Gottingen, Germany), UV-visible spectroscopy (Shimadzu, Tokyo, Japan) and X-ray diffraction XRD (SIEMENS-D5000, Karlsruhe, Germany). For synthesizing of SPION@Au-CS-DOX-FA, SPION@Au was coated with CS and FA using a previous method with some modification [23]. In brief, $250 \mathrm{mg}$ of CS (Mw $=50-190 \mathrm{kDa})$ was added to $17.5 \mathrm{~mL}$ of acetic acid $(1 \%, v / v)$ under stirring for $15 \mathrm{~min}$ at room temperature until a homogeneous solution was obtained. The prepared solution was then applied to the SPION@Au NPs. Afterward, $50 \mathrm{mg}$ of DOX $(1 \mathrm{mg} / \mathrm{mL})$ drug was dissolved in $25 \mathrm{~mL}$ of distilled water and added to the SPION@Au-CS-DOX-FA solution. FA (25 mg) was previously dissolved in $(5 \mathrm{~mL})$ distilled water. Approximately $50 \mu \mathrm{L}$ of $\mathrm{NaOH}$ solution $(10 \mathrm{M})$ was mixed under magnetic stirring, and $0.5 \mathrm{~mL}$ of the prepared FA was obtained. The solution was mixed with $5 \mathrm{~mL}(1 \mathrm{mg} / \mathrm{mL})$ of SPION@Au-CS-DOX-FA NPs. The solution was incubated at room temperature in a shaking incubator (300 rpm) for two h to facilitate DOX uptake in SPION@Au-CS-FA NPs. Optical density (OD) for DOX residual in the supernatant was measured using a UV-vis spectrometer device on $498 \mathrm{~nm}$. 


\subsection{Size and Morphological Characteristics of Prepared NPs}

Zeta potential analyzer (Malvern Instruments Ltd., Malvern, UK) was used to detect the NPs average size diameter, polydispersity index (PDI), and zeta potentials. SPION@AuCS-DOX-FA was also analyzed by AFM (OMCL-RC800PSA-1, Olympus, Tokyo, Japan) at room temperature using a drop of fresh solution on silicon that was left to dry. SEM was characterized after sputter coating with Au for samples, and TEM at $200 \mathrm{kV}$ accelerating voltage was employed to observe the morphological characteristics of SPION@Au-CSDOX-FA. The samples were prepared by sticking a drop of dispersed particle suspension on the carbon-coated copper grid and allowing it to dry at room temperature. Furthermore, the prepared SPION@Au-CS-DOX-FA was evaluated by Fourier transform infrared spectra (FTIR, Shimadzu Corporation, Tokyo, Japan) in the range of $4000-400 \mathrm{~cm}^{-1}$. A vibrating sample magnetometer (VSM) was used to perform magnetic tests at room temperature.

\subsection{Determination of Release Profile and DOX Calibration Curve}

The DOX drug released from loaded SPION@Au-CS-FA NPs was studied under in vitro conditions using phosphate buffer $(0.01 \mathrm{M}, \mathrm{pH} 7.4)$ and citrate buffer $(0.01 \mathrm{M}$, $\mathrm{pH}$ 5.4) containing $2 \mathrm{M}$ sodium salicylate in a shaker incubator at $37^{\circ} \mathrm{C}$. In brief, $1 \mathrm{~mL}$ of nanoparticle solution was placed in a dialyze bag placed in $100 \mathrm{~mL}$ of citrate or phosphate buffer. Tween 80 was selected as a surfactant agent to emulsify and inhibit the sedimentation volume from a released drug. UV-vis measurement was used to measure the DOX loading efficiency. The following Equation (1) can measure the loading content (LC \%) and loading efficiency (LE \%) of DOX:

$$
\text { Encapsulation Efficiency }(\%)=\frac{(\text { Total amount of drug }- \text { Free amount of drug })}{\text { Total amount of drug }} \times 100
$$

\subsection{Cell Culture}

$\mathrm{SkBr} 3$ and MCF-10A cell lines were cultured in $100 \mathrm{~mL}$ culture flasks using Dulbecco's modified Eagle medium (DMEM) cell culture medium, 10\% phosphate-buffered saline (PBS), and $1 \%$ penicillin-streptomycin $\left(1 \times 10^{4}\right.$ units per $\left.\mathrm{mL}\right)$. The culture was incubated at $37^{\circ} \mathrm{C}$ in a humidified atmosphere containing $5 \% \mathrm{CO}_{2}$.

\section{Cellular Internalization}

SPION@Au-CS-DOX-FA was functionalized with fluorescein 5(6)-Isothiocyanate (FITC) to evaluate its cell internalization efficiency using a fluorescence microscope (Nikon Eclipse TE2000-U, Temecula, CA, USA). The fluorescein isothiocyanate (FITC)-chitosan was synthesized by coupling fluorescein isothiocyanate (5-isomer) to chitosan polymer through a reaction between FITC's isothiocyanate group and the primary chitosan amino group. For the analysis of cellular internalization, FITC-SPION@Au-CS-DOX-FA was examined in $\mathrm{SkBr} 3$ and MCF-10A cell lines through fluorescent emission from DOX in cell medium. The cells were seeded with DMEM medium on coverslips in six-well plates to allow attachment overnight. The medium was detached and washed by (PBS) The cells were treated with FITC-SPION@Au-CS-DOX-FA for $4 \mathrm{~h}$ at $37^{\circ} \mathrm{C}$. After incubation, the medium was removed, and the cells were washed with PBS three times. Coverslips were placed on a microscope slide. The cells were treated with $5 \mathrm{~g}$ of FITC-SPION@Au-CS-DOX-FA for $3 \mathrm{~h}$. Subsequently, the nanocomposite-containing medium was discarded, and the cells were washed with PBS.

\subsection{MTT Assay}

The potential cell toxicity of SPION@Au-CS-DOX-FA was examined using MTT assay. SkBr3 and MCF-10A cells were seeded into 96-well plates at a density of $5 \times 10^{4}$ cells per well and incubated for $24 \mathrm{~h}$ in DMEM culture medium, which was then removed and replaced by a new one with different concentrations of SPION@Au-CS-DOX-FA suspension. DOX concentrations ranging from $4 \mu \mathrm{g} / \mathrm{mL}$ to $20 \mu \mathrm{g} / \mathrm{mL}$ were added to 
the wells. The cell cultures were incubated at $37^{\circ} \mathrm{C}$ for $24 \mathrm{~h}$, and $20 \mu \mathrm{L}$ of MTT $(5 \mathrm{mg} / \mathrm{mL}$ in PBS pH 7.4) was added to each well and incubated for $4 \mathrm{~h}$. The upper-medium from wells was gently removed, and $150 \mu \mathrm{L}$ of DMSO was added. The suspension was vigorously mixed, transferred into microtubes, and centrifuged at 13,000 rpm for $10 \mathrm{~min}$. Absorbance was read using a microplate reader (BioTek Power Wave XS, VT, USA) at $570 \mathrm{~nm}$.

\subsection{Flow Cytometry Test}

Annexin V-FITC kit (Beyotime, Biotechnology Co., Ltd., Nantong, China) was used to calculate the percentage of cells rapidly undergoing apoptosis by flow cytometry in accordance with the manufacturer's instructions. The culture plated of SkBr3 and MCF-10A were resuspended in binding buffer. The cells at a density of $10^{3}$ cells/well were combined with $5 \mu \mathrm{L}$ of Annexin V-FITC and $5 \mu \mathrm{L}$ of PI. At room temperature, the cells were then incubated in the dark for $15 \mathrm{~min}$. Flow cytometry was conducted using the FACSCalibur ${ }^{\mathrm{TM}}$ system (BD Biosciences, Franklin Lakes, NJ, USA).

\subsection{Apoptosis Detection by Quantitative Real-Time PCR}

2.8.1. Total Isolation of RNA and Complementary DNA Synthesis

cDNA (Fermentas, Hanover, Germany) was synthesized directly from extracted total RNA through reverse transcription following the instruction protocol.

\subsubsection{Quantitative Real-Time PCR Reaction}

Primers for target and endogenous genes (Bcl-2, Bcl-xl, Bak, and BAX) were designed using software primer express (Table 1). PCR primers (forward and reverse sequences) were obtained from previous studies [24-27], and $\beta$-actin was employed as a housekeeping gene for normalizing the cDNA variation. The gene expression was studied using RT-PCR (Applied Biosystems, Foster City, CA, USA).

Table 1. Sequences of primers oligonucleotides used to amplify the studied genes.

\begin{tabular}{ccccc}
\hline Gene & Forward Primer Sequence & Reverse Primer Sequence & Ref. \\
\hline$\beta$-actin & $5^{\prime}$-CTGGCACCCAGCACAATG-3' & $5^{\prime}$-GCCGATCCACACGGAGTACT-3' & [24] \\
\hline Bcl-2 & $5^{\prime}$-TGCCTTTGTGGAACTGTACG-3' & $5^{\prime}$-GGCCAAACTGAGCAGAGTC-3' & [25] \\
\hline BAX & $5^{\prime}$-AGCTGCAGAGGATGATTGC-3' & $5^{\prime}$-GTTGAAGTTGCCGTCAGAAA-3' & [25] \\
\hline Bcl-xl & $5^{\prime}$-AAGGAGATGCAGGTATTGGTGAGT-3' & $5^{\prime}$-CCAAGGCTCTAGGTGGTCATTC-3' & [26] \\
\hline Bak & $5^{\prime}$-ACTGGGATCGAGACATGTG-3' & $5^{\prime}$-AGAAGGTGATGTGTACATTGC-3' & [27] \\
\hline
\end{tabular}

\subsection{In Vivo Study}

\subsubsection{Animal Use}

NOD.CB17-Prkdcscid/J mice 6-8 weeks old and weighing $25 \mathrm{~g}$ were acquired from the animal house. The guideline approved animal care and use of Animal Care and Research Committee of Al-Qasim Green University (ethics committee approval code: 533FD2) was adopted from the guideline for the care and use of laboratory animals. All in vivo protocols and methods were performed by pertinent guidelines and regulations. Moreover, all experimental procedures were confirmed by an Animal Care and Research Committee of Al-Qasim Green University.

\subsubsection{Tumor Volume and Survival Rate Studies}

A total of $1 \times 10^{6} \mathrm{SkBr} 3$ exponentially growing cells $/ 200 \mu \mathrm{L}$ of PBS-free medium were injected subcutaneously (s.c.) in NOD.CB17-Prkdcscid/J mice. Tumor mass was confirmed on day 8 due to the fast growth and offensive characteristics of the $\mathrm{SkBr} 3$ cell line. The animals were divided randomly into four groups ( $n=7$ per group), including 
three test groups intravenously receiving $12.5 \mathrm{mg} / \mathrm{kg}$ body weight DOX loaded NPs and free DOX for 3 weeks and three control groups including SPION@Au-CS-DOX-FA and PBS.

Tumor volume $\left(\mathrm{mm}^{3}\right)$ was calculated three times per week using a digital Vernier caliper (Mitutoyo, Japan) using the Equation (2).

$$
\text { Tumor volume }=\frac{1}{2}\left[\text { Tumor length } \times(\text { Tumor width })^{2}\right]
$$

\subsection{Splenocyte Proliferation Index}

The mice were sacrificed, and a part of the spleen from each animal was isolated. Splenocyte proliferation index was calculated using the method of Babaei et al. [28]. The spleens were removed, cleaned with PBS, homogenized, and passed through a $100 \mu \mathrm{M}$ filter to acquire a single-cell suspension. The cells were centrifuged, and the trypan blue exclusion test was used to determine viable splenocytes. The tumor cell lysate was used as a positive control, and the medium served as a negative control. MTT assay was used to determine the splenocyte proliferation index. Each experiment was accomplished in triplicate wells.

\subsection{Cytokine Detection by ELISA}

The splenocytes were incubated with tumor lysate to test their effects on the cytokine release. Phytohemagglutinin (PHA) was added as a positive control, and the medium was used as a negative control. ELISA kit (R\&D, Minneapolis, MN, USA) was used to collect and test the supernatant for Interferon-Gamma (IFN- $\gamma$ ) and Interleukin 4 (IL-4).

\subsection{Statistical Analysis}

Statistics analysis was conducted by one-way ANOVA and unpaired students t-test by using Tukey's multiple comparisons. Significance level was set at ${ }^{*} p<0.05$; ${ }^{* *} p<0.01$, and ${ }^{* * *} p<0.001$.

\section{Results and Discussion}

A multilayered nanocomposite named SPION@Au platform was prepared through microemulsion, stabilized by biocompatible CS, and conjugated with targeting FA. DOX chemotherapeutic drug was loaded, and their synergistic action for tumor therapy was evaluated. Chemical co-precipitation was adopted to generate SPIONs because it allows for feasible large-scale and relatively low-cost production [29]. Au shell protects SPION against oxidation and makes it sensitive to light absorption [30]. CS was used as a stabilizing factor in the presence of FA for nanoparticle surface modification to prevent SPION agglomeration [31]. DOX-loaded FA-CS-SPION@Au NPs had a size particle average of $102.6 \pm 7 \mathrm{~nm}$. Encapsulation was performed under the electrostatic load capacity of DOX to SPION@Au-CS-FA NPs by using the electrostatic interaction between the carboxyl group of carboxylic acid-functional iron-oxide NPs and the DOX amine group [32].

\subsection{Characterization of SPION@Au-CS-DOX-FA}

The prepared SPION@Au-CS-DOX-FA core-shell NPs had a spherical shape and uniform size as observed by AFM, TEM, and SEM (Figure 1a-c). An average diameter of $102.6 \pm 7 \mathrm{~nm}$ with single peak shape and narrow particle size distribution (Figure 1d) with zeta potential $-63.1 \pm 6 \mathrm{mV}$ in the neutral environment of $\mathrm{pH}$ 7.4 (Figure 1e). Additionally, the changes in the surface plasmon resonance (SPR) band were found in the SPION, and SPION@Au spectra as shown by UV visible spectroscopy (Figure 2a). The absorption of pure SPION decreased with the wavelength of light. The large SPR bands with a wavelength peak range from $550 \mathrm{~nm}$ to $650 \mathrm{~nm}$ often indicate Au shell's presence on the surface of SPION. Figure $2 \mathrm{~b}$ displays the powder X-ray diffraction (XRD) patterns of the SPION and SPION@Au core-shell NPs. The diffraction angle of the raw SPION (311) peak occurs at $39.51^{\circ}$, which means that the SPION composition is magnetite before the Au shell is reduced. After encapsulating SPION with Au, the XRD signals shift to (111) 
indicated the $\mathrm{Au}$ shell formation on the surface of SPION. The XRD signals of the $\mathrm{Fe}_{3} \mathrm{O}_{4}$ core were shielded by the gold layer because of the heavy atom effect. Alteration in the chemical structures of NPs resulted in differences in dynamic light scattering (DLS) and zeta potential values (Table 2).
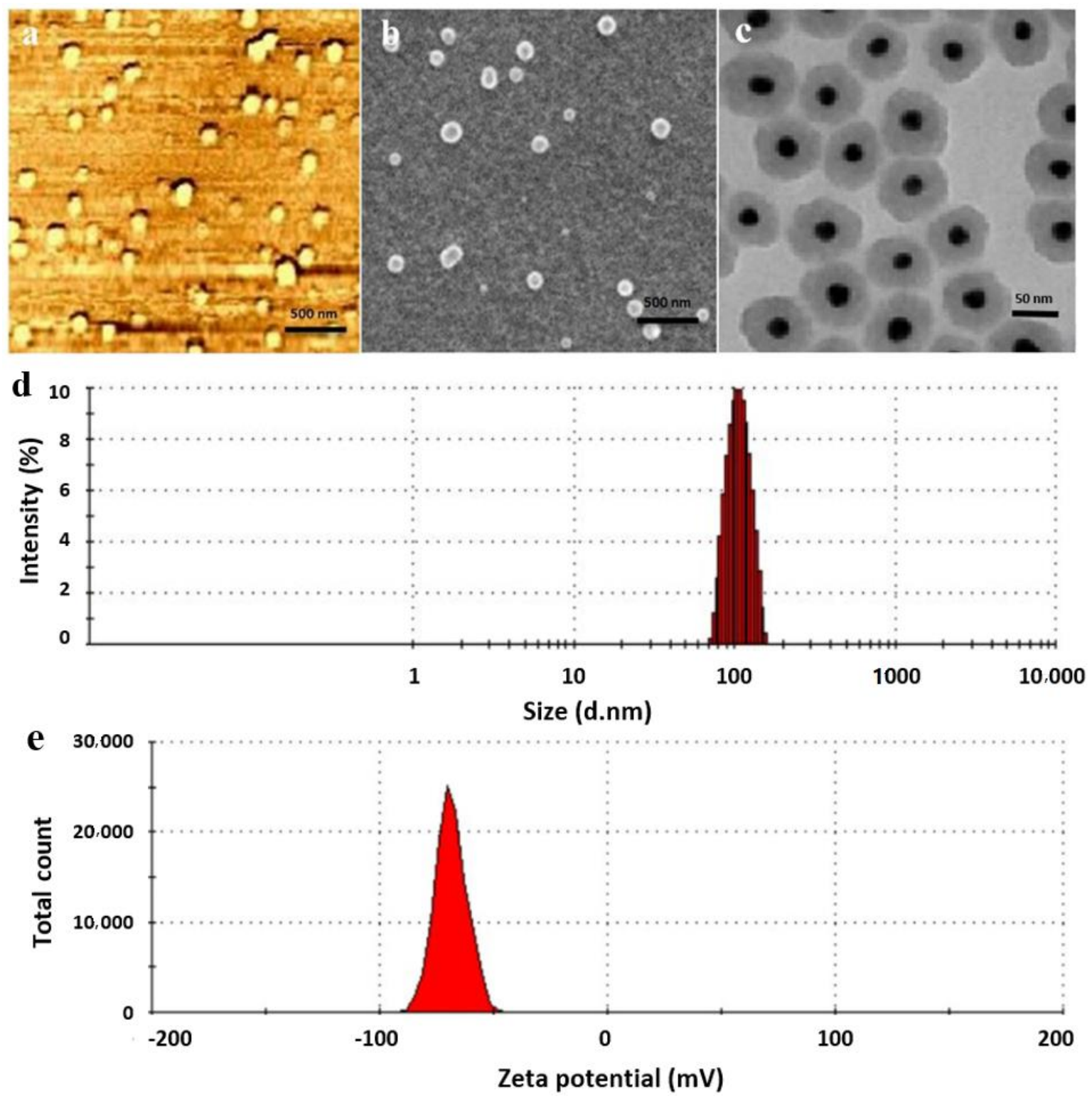

Figure 1. Characterization of the designed (SPION@Au-CS-FA nanocomposite) with different techniques. (a) atomic force microscope (AFM), (b) scanning electron microscope (SEM), (c) transmission electron microscope (TEM) images, (d) the particle size distribution of SPION@Au-CS-FA and (e) charge measurement uses dynamic light scattering (DLS). Abbreviations: FA: Folate, CS: Chitosan, SPION: Superparamagnetic iron oxide nanoparticles (NPs), and Au: Gold.

Table 2. Hydrodynamic scale and zeta potential parameters of the synthesized NPs.

\begin{tabular}{cccccr}
\hline & SPION & SPION@Au & SPION@Au-CS & SPION@Au-CS-FA & SPION@Au-CS-DOX-FA \\
\hline Size & $23.1 \pm 2$ & $37.3 \pm 3$ & $68.3 \pm 6$ & $81.8 \pm 3$ & $102.6 \pm 7$ \\
\hline Zeta & $-35.2 \pm 2$ & $-43.4 \pm 7$ & $50.2 \pm 3$ & $24.8 \pm 4$ & $-63.1 \pm 6$ \\
\hline
\end{tabular}


a
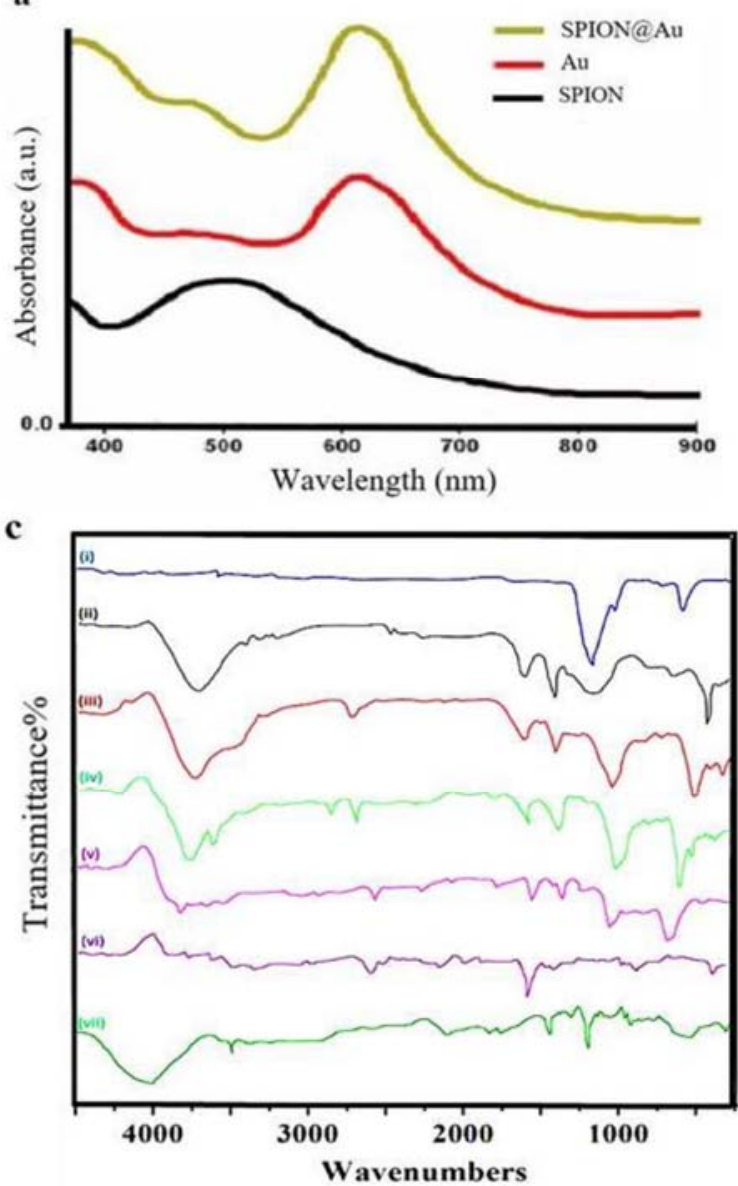

b
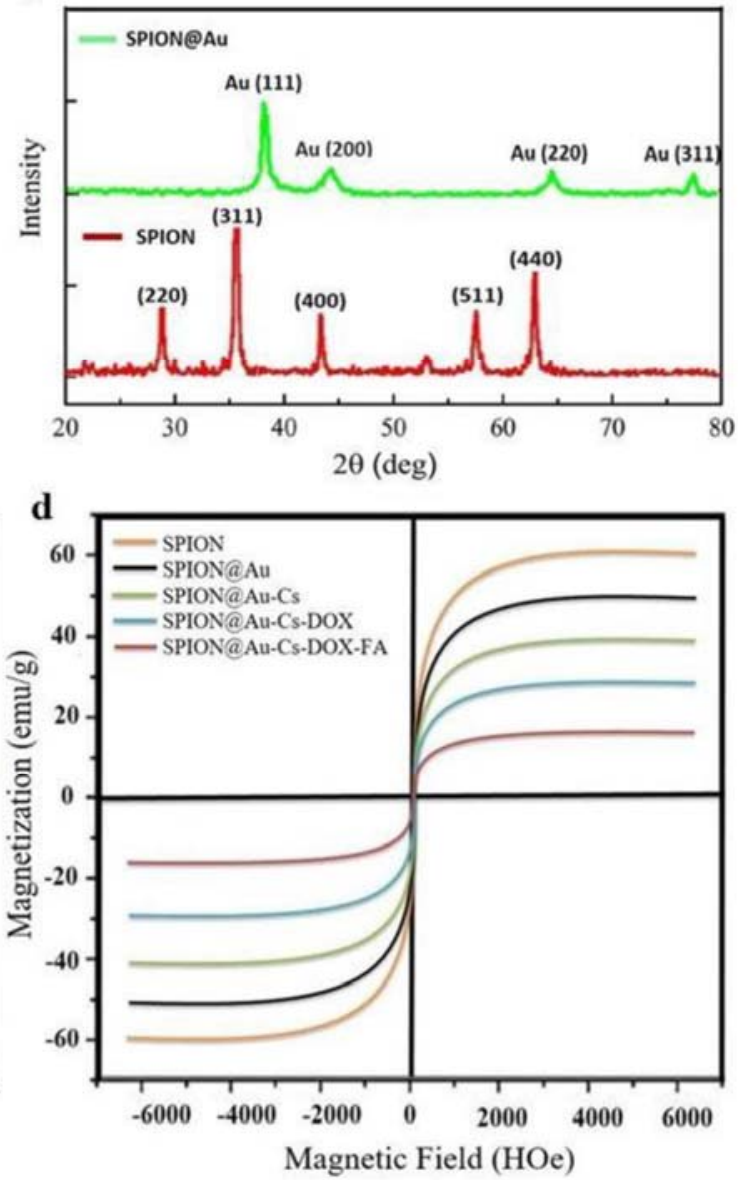

Figure 2. UV visible (a) and XRD (b) characterization of the prepared SPION@Au core-shell NPs. FT-IR spectra (c) of the prepared SPION@Au-CS-doxorubicin (DOX)-FA NPs. Au (i), SPION (ii), SPION@Au-Cs (iii) SPION@Au-CS-DOX-FA (iv), and DOX (v), FA (vi) Cs (vii) magnetic hysteresis curve (d) of the prepared SPION@Au-CS-DOX-FA NPs.

The nanoscale is important because nanocarrier systems containing anti-cancer drugs can easily target and accumulate within the tumor's area by exerting cytotoxic effects on proliferating cells [33]. FTIR confirmed that the prepared NPs contained uncoated SPION, SPION@Au, FA, and CS NPs. The spectra for SPION, Au, CS, DOX, and FA are illustrated in (Figure 2a). Absorption peaks were found at $\left(443,583\right.$, and $\left.634 \mathrm{~cm}^{-1}\right)$ and can be related to the $\mathrm{Fe}-\mathrm{O}$ bond [34]. The band at $3455.8 \mathrm{~cm}^{-1}$ was related to the stretching vibration. O-H group in citrate capped SPION@Au range, and its intensity was lower than that in the uncoated $\mathrm{Fe}_{3} \mathrm{O}_{4}$ because of Au coating. $\mathrm{CH} 2$ stretching allows the average intensity up to $3016.7 \mathrm{~cm}^{-1}$ [35]. CS FTIR spectrum showed a band that corresponded to the O-H stretch at $\sim 3484 \mathrm{~cm}^{-1}$. The amide group in CS was evident from its peak of absorption at $\sim 1660 \mathrm{~cm}^{-1}$ [36]. In addition, the FTIR FA spectrum showed IR bands at 1480-1700 $\mathrm{cm}^{-1}$ corresponding to $\mathrm{C}=\mathrm{N}$ bonds, $\mathrm{C}=\mathrm{O}$, and the $\mathrm{NH}_{2}$-pteridine ring group in folate [37]. VSM was used to study the magnetic activity of the SPION@Au-CS-FA NPs (Figure 2b). This finding revealed the superparamagnetic properties of SPION@Au-CS-FA NPs with a saturation magnetization value of $51.2 \mathrm{emu} / \mathrm{gm}$. The rapid response to the external magnetic field, the stable formulation, and the desired stability of SPIONs in solution make these particles suitable nanocarriers [38]. The capacity of SPION@Au-CS-FA NPs for DOX release was studied under different $\mathrm{pH}$ conditions of 5.4 and 7.4 at $37{ }^{\circ} \mathrm{C}$ in PBS [39]. The amounts of (DOX) drug released from FA-CS-SPION@Au NPs were detected by calculating the supernatant's fluorescent emission intensity at various $\mathrm{pH}$ values (Figure 3a). The $\mathrm{pH}$ of the culture medium was found vital for the release capacity of DOX from FA-CS-SPION@Au NPs. The $\mathrm{pH}$ values for evaluating drug release were 
selected based on the physiological and endosomal $\mathrm{pH}$ value of cancer cells. Drug release curves showed that the release time from loaded SPION@Au-CS-DOX-FA within $96 \mathrm{~h}$ was slower when treated with a phosphate buffer in normal $\mathrm{pH}(\mathrm{pH} 7.4)$ compared with that under acidic citrate buffer a $\mathrm{pH}$ value of ( $\mathrm{pH}$ 5.4). By contrast, the in vitro release profiles of free DOX indicated an analogous release algorithm in (pH 7.4 and 5.4). These curve results revealed a faster DOX release rate in $\mathrm{pH} 5.4$ at similar conditions compared with that in $\mathrm{pH} 7.4$.

\subsection{Cellular Uptake Ability}

The release amount of DOX drug-loaded SPION@Au-CS-DOX-FA NPs was internalized into the cytoplasm of the SkBr3 cell line, as shown in (Figure 3b-e) respectively. This is shown by the incremental enhancement of the DOX loaded green fluorescence SPION@Au-CS-DOX-FA NPs from 0 to 6 h. Besides, green fluorescence has been shown to emanate only from the internalized NPs.

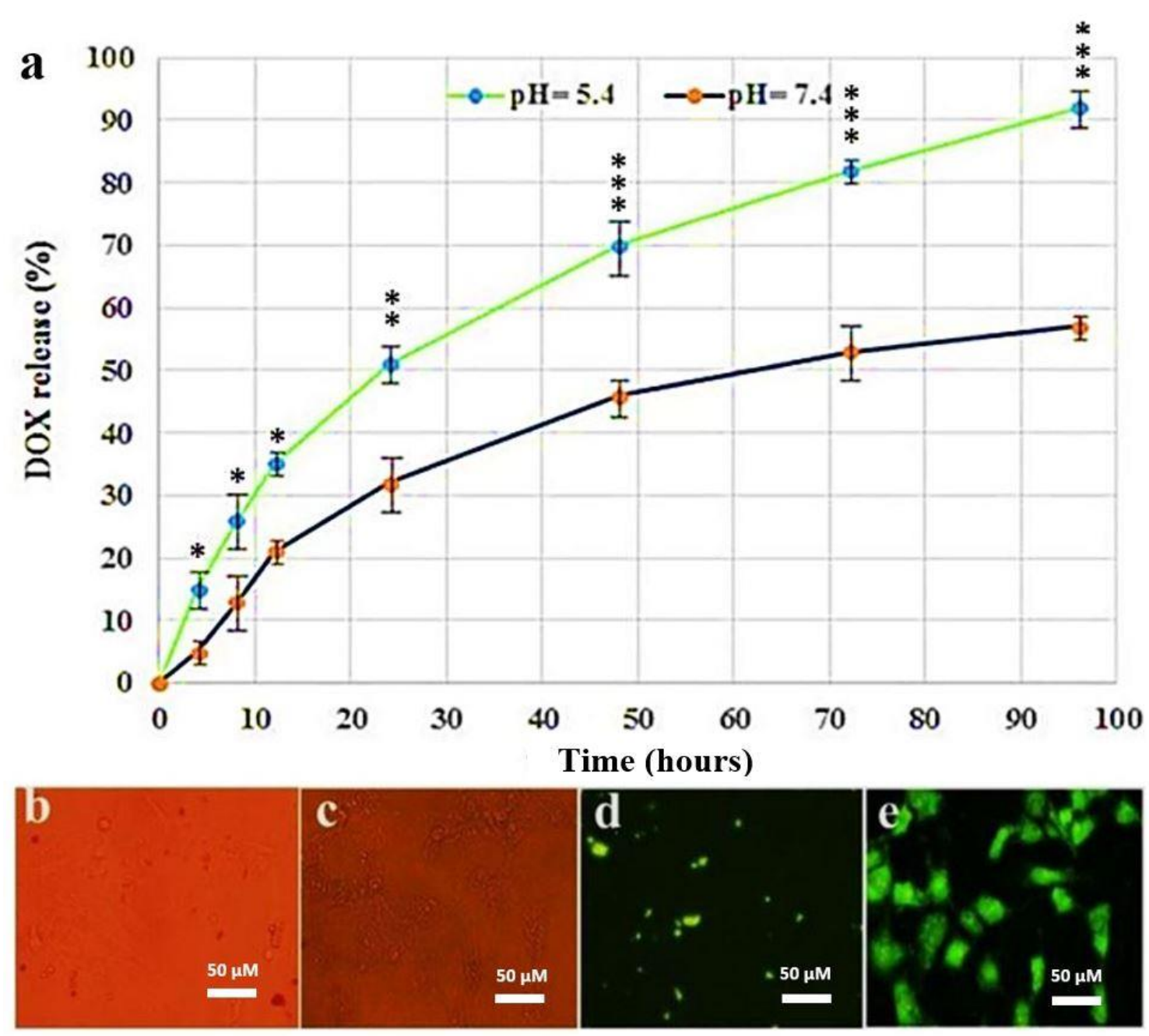

Figure 3. In vitro release profile of DOX from SPION@Au-CS-FA NPs at different $\mathrm{pH}$ values and the intracellular uptake. (a) the release rate of SPION@Au-CS-DOX-FA NPs at pH 7.4 and pH 5.4. All experiments were performed at $37^{\circ} \mathrm{C}$. The data represent mean \pm S.D., $\left.\left({ }^{*} p<0.05 ;{ }^{* *} p<0.01 ;{ }^{* *} p<0.001\right) ; \mathrm{n}=3\right)$. (b) optical microscopy image of SPION@Au-CS-DOX-FA treated cells. (c) Optical microscopy image of free DOX. (d) fluorescence microscopy image of SPION@Au-CS-DOX-FA treated cells. (e) fluorescence microscopy image of free DOX. 


\subsection{MTT Assay}

The in vitro cell toxicity of SPION@Au-CS-DOX-FA was examined by MTT assay against SKBR3 and MCF-10A cell lines (Figure 4). The cancer cells were treated with free DOX and bare SPION@Au-CS-FA. Even at the highest concentration of $60 \mu \mathrm{M}$, no toxicity for cells was observed, and more than $85 \%$ of cells still survived after $48 \mathrm{~h}$ of incubation, which indicated cytocompatibility. Besides, SPION@Au-CS-DOX-FA significantly decreased cell viability and induced higher inhibition activity of cancer cells compared with free DOX and bare SPION@Au-CS-DOX-FA NPs alone. IC S0 $_{50}$ concentration was determined by a dose-response curve fitting of the cell viability date. The $\mathrm{IC}_{50}$ values for SPION@Au-CS-DOX-FA NPs for SK BR3 cancer cell line within 24 and $48 \mathrm{~h}$ were 29.11 and $14.68 \mu \mathrm{M}$, respectively. This phenomenon occurred because apoptosis was more intense than necrosis after the treatment with SPION@Au-CS-DOX-FA NPs.

Furthermore, the same concentrations of $\mathrm{SkBr} 3$ cancer cells did not affect the proliferation of MCF-10A cells even at $60 \mu \mathrm{M}$, indicating the safe use of these NPs. The use of NPs as capsules for anti-cancer drugs can facilitate their intake by the cells and lysosomes, leading to a highly induced cytotoxic activity [40]. One previous investigation indicated that SPIONs dose-dependently increases toxicity [41]. However, elucidating the mechanism underlying the anti-proliferative potentials of SPION@Au-CS-DOX-FA is essential for standardizing and developing an efficient treatment regime.
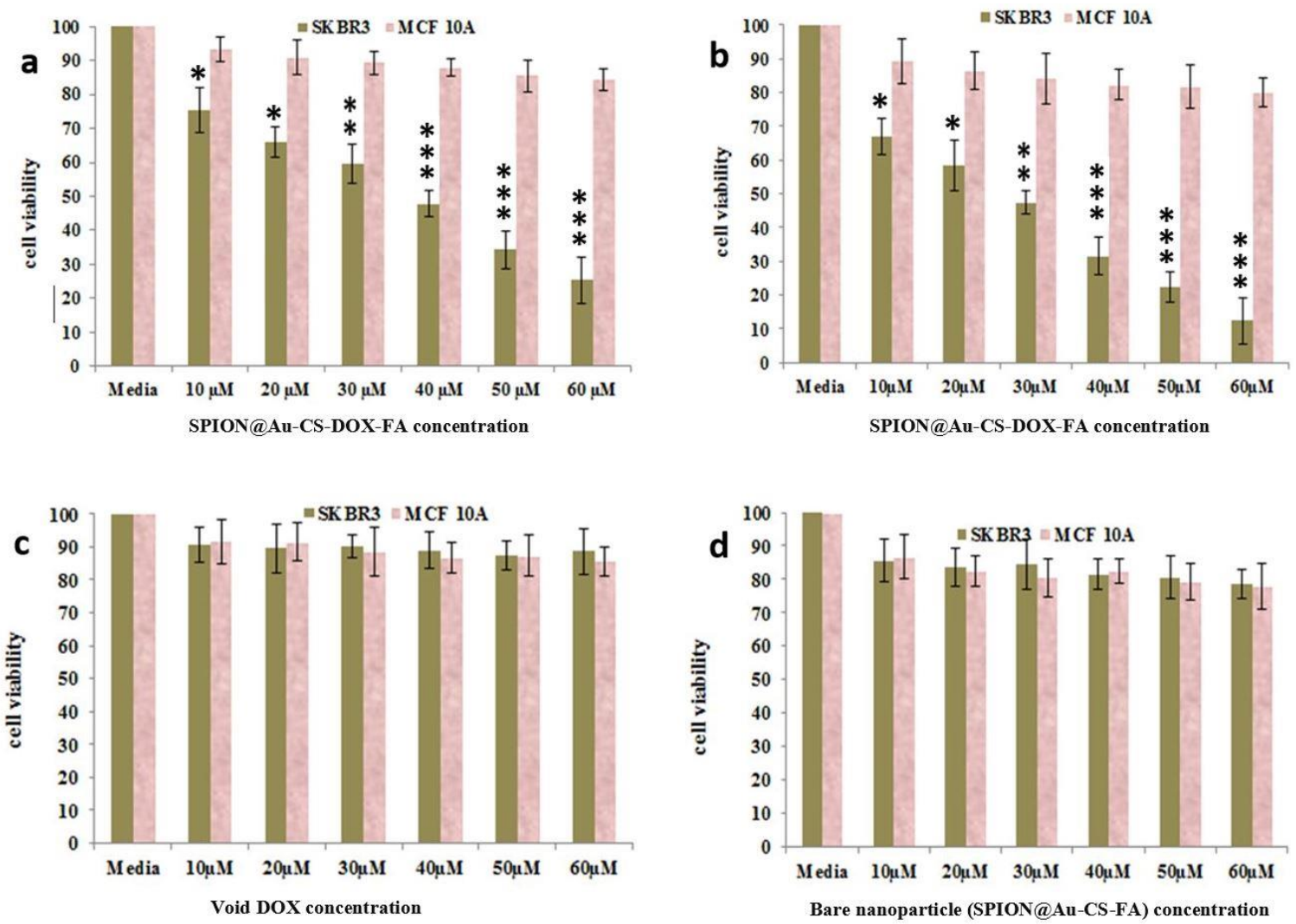

Figure 4. Cell toxicity evaluation of SPION@Au-CS-DOX-FA nanoformulation by the MTT assay on SKBR3 and MCF-10A

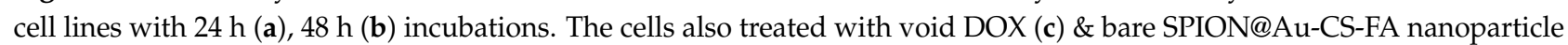
(d) with same concentrations for 48 h. (mean \pm S.D., $\left({ }^{*} p<0.05 ;{ }^{* *} p<0.01 ;{ }^{* * *} p<0.001\right)$; $\mathrm{n}=3$ ).

\subsection{Flow Cytometry}

The apoptosis of SkBr3 and MCF-10A cell line cultures was analyzed using flow cytometry. For the cell death onset analysis, SkBr3 (Figure 5a and MCF-10A (Figure 5b) cell lines were handled for $48 \mathrm{~h}$ separately using SPION@Au-CS-FA, DOX, and SPION@Au-CS- 
DOX-FA. Apoptotic cell death was analyzed and studied by flow cytometry by staining the cells with Annexin-V-FITC. The results showed a dose-dependent induction in these two cell lines of early or late death of apoptotic cells as present in (Figure 5). Compared with MCF-10A cells, SK-BR3 cells exhibited more cell death with a percentage of $22.4 \%$ apoptosis following the administration of SPION@Au-CS-DOX-FA (5 $\mu \mathrm{M} ; p<0.05)$. Meanwhile, 6.4\% apoptosis was observed in MCF-10A cells under the same conditions $(p<0.05)$, suggesting that SPION@Au-CS-DOX-FA could greatly increase the DOX-induced apoptosis in breast cancer cells. Annexin V-FITC binds with a high affinity ideally to phosphatidylserine and therefore, can be used to determine the degree of apoptosis [42]. The number of cells in the early and/or late stage of apoptosis was quantified with PI staining. The results suggest that SPION@Au-CS-DOX-FA increases the DOX sensitivity of SkBr3 cells and significantly induces apoptosis in cancer cells (Figure 5a).
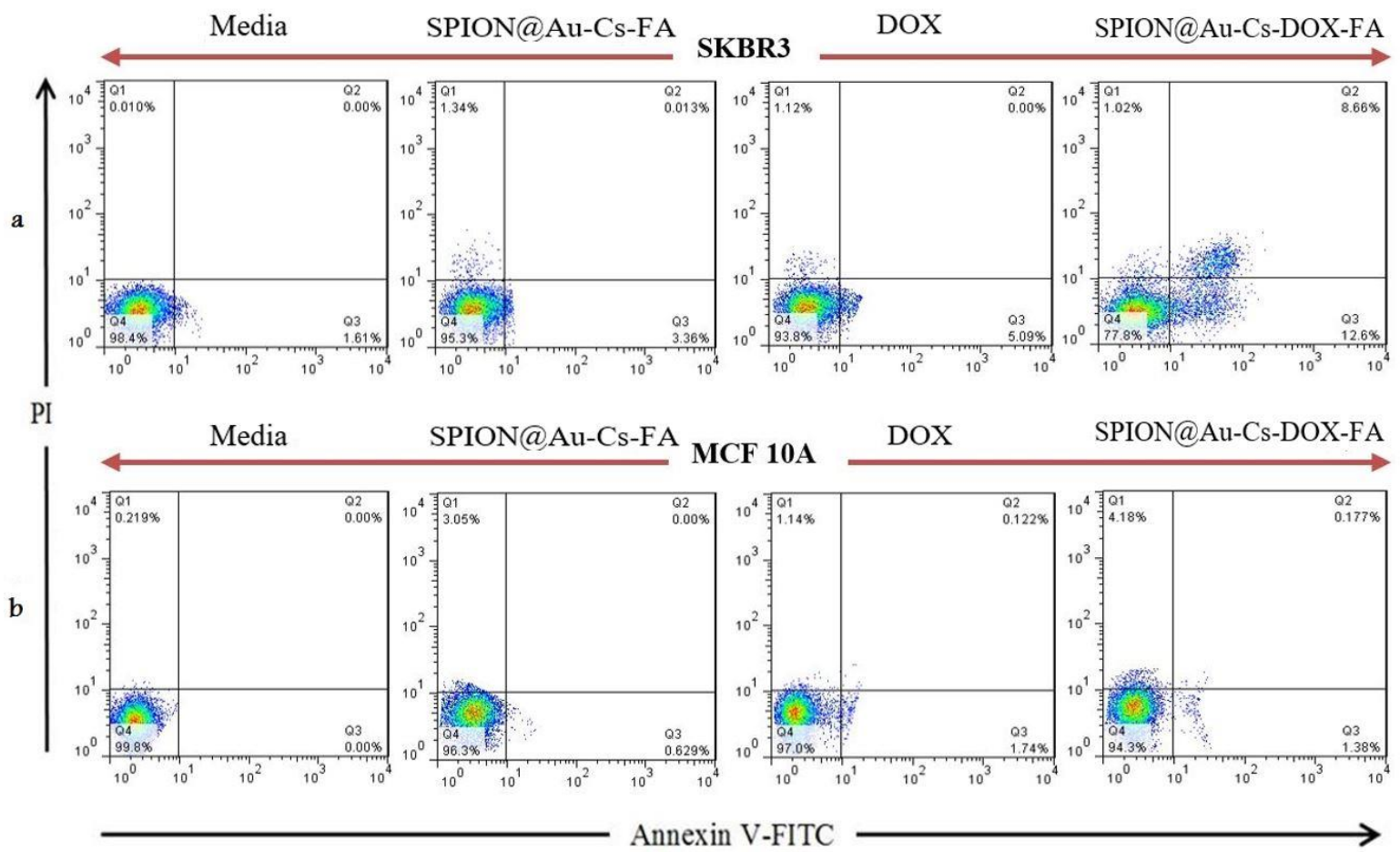

Figure 5. Apoptosis induction of SkBR3 (a) and MCF-10A (b) cell lines with media (control), bare SPION@Au-CS-FA NPs, free DOX and SPION@Au-CS-DOX-FA. The number of SkBR3 cells undergoing apoptosis significantly increases when treated with SPION@Au-CS-DOX-FA. Treatment of SkBr3 cell line with bare SPION@Au-CS-FA and free DOX separately, indicating that both treatments did not show any remarkable apoptosis induction.

\subsection{Real-Time PCR and Gene Expression}

After treatment with FA-CS-DOX-SPION-Au, the expression level of the selected genes was compared between SkBr3 cell lines treated with SPION@Au-CS-FA and DOX individually. The statistical study of real-time PCR revealed that after treatment, FA-CSDOX-SPION-Au significantly decreased the expression of Bcl-2 and Bcl-xl by 0.32-fold $(p<0.001)$ and 0.18 -fold $(p<0.0001)$, respectively, compared with those of the control group (untreated). Moreover, FA-CS-DOX-SPION-Au considerably $(p<0.0001)$ up-regulated the expression of BAK by 2.97 and Bax by 2.58-fold of normal levels $(p<0.01$, Figure 6$)$. In general, B-cell lymphoma 2 (BCL-2) is a family of receptor proteins that regulate apoptosis via proteins pro-apoptotic (Bax, Bad, and Bak) and anti-apoptotic (BCL-2 proper, BCL$\mathrm{XL}$, and MCL), anti-apoptotic protein overexpression leads to treatment resistance [43]. These findings indicated that DOX anti-cancer drug-loaded FA-CS-SPION-Au NPs induce apoptosis by regulating the family Bcl-2 proteins. 


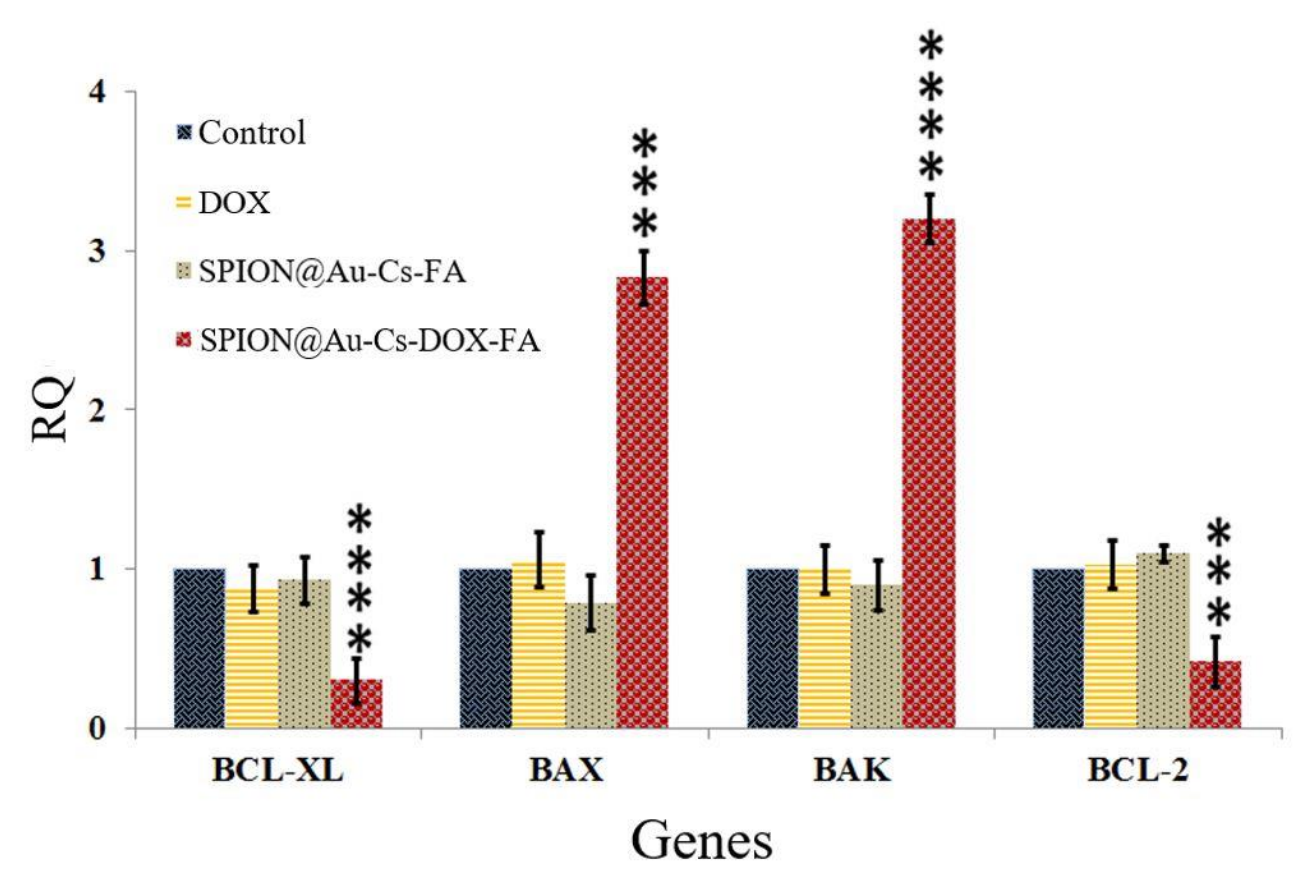

Figure 6. Gene expression of BCL-XL, BAX, BAK, and BCL-2 have been analyzed in four groups of $\mathrm{SkBr} 3$ cells. In each group, the first column represents control cells, the second column for cells treated with DOX, the third column for cells treated with SPION@Au-CS-FA, and the fourth column for cells treated with SPION@Au-CS-DOX-FA. The values in the graph indicate the mean \pm SD. ${ }^{* * *} p<0.001,{ }^{* * *} p<0.0001$ represent significant differences between the control (untreated) and other treatments.

\subsection{Effect of SPION@Au-CS-DOX-FA on Tumor Volume and Survival Rate}

The tumor volume changes in representational mice (four groups) are shown in Figure 7a. On day 19, the tumor growth in mice treated with SPION@Au-CS-DOX-FA was reduced significantly $(p<0.01)$ relative to that of the other groups receiving free DOX, SPION@Au-CS-FA NPs, and PBS. Small particles in the tumor can pass easily through the capillary wall but can also be pushed out of the tumor by blood flow. Given that the magnetic force acting on the magnetic particles is proportional to the particle volume, the fluidic drag force may overcome the magnetic force experienced by the small particles [44].

\subsection{Evaluation of the Lymphocyte Proliferation Index Following Treatment}

All four groups of mice were examined for the proliferation index of splenocytes following the induction of tumor lysate, PHA (positive control), and medium (negative control). Significantly, high levels of splenocyte proliferation were found in the mice received the nanoformulations of SPION@Au-CS-DOX-FA compared with those of three other classes $(p<0.05$, Figure 7c). By contrast, the splenocytes from the other three groups showed no significant differences.

\subsection{Estimation of IFN- $\gamma$ and IL-4 Level Post-Treatment}

Figure 7c,d suggested that the splenocytes collected from mice treated with SPION@AuCS-DOX-FA were re-stimulated with tumor lysate and showed a substantial increase $(p<0.05)$ in IFN- $\gamma$ levels compared with the other groups. However, the average level in all samples was slightly small. A significant decrease $(p<0.05)$ in IL-4 production was observed in the mice received SPION@Au-CS-DOX-FA nanoformulation compared with those taken DOX, SPION@Au-CS-FA, and PBS. Stimulated sample results for the PHA (positive control) and medium (negative control) showed no significant differences between the groups. SPION@Au-CS-DOX-FA NPs showed antitumor properties and influenced the immune system. The proliferative index of splenocytes and secretion of IFN- $\gamma$ and IL-4 cytokines were also investigated. Such findings are in agreement with other previous studies 
suggesting a strong association between the antitumor effect of DOX-loaded polymeric nanocarrier and immune reactions, including splenocytes proliferation and cytokine production $[45,46]$. In addition, changes in cytokine development, such as antitumor response are correlated with IFN- $\gamma$ [47].

a
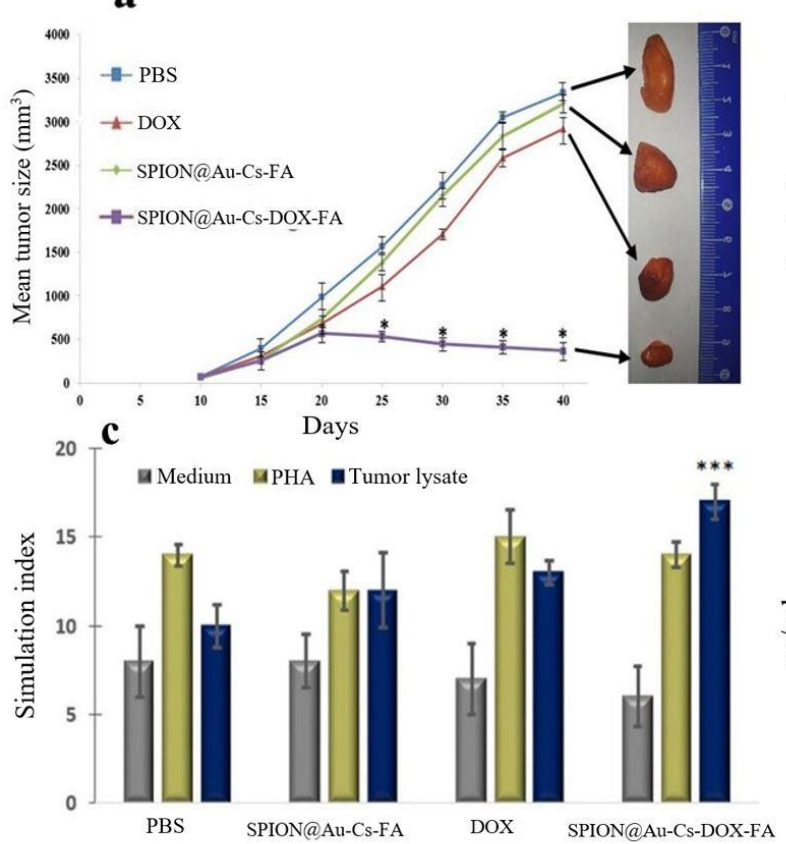

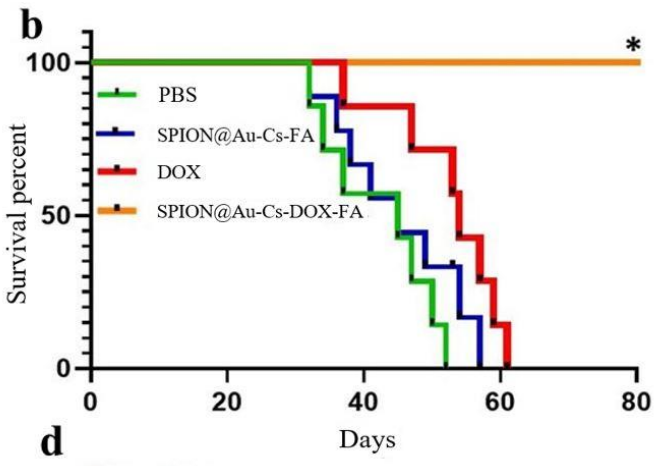

INF-

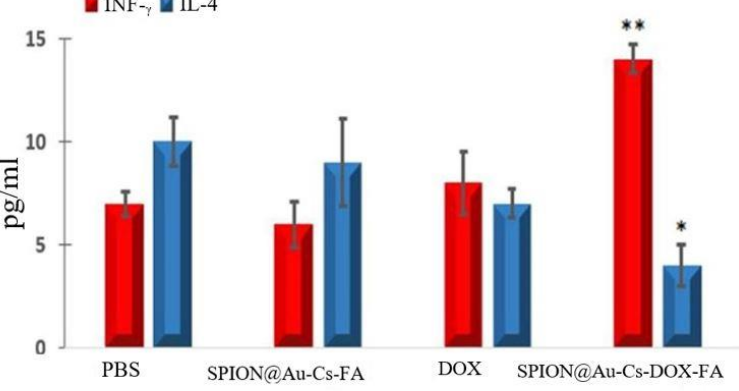

Figure 7. The in vivo antitumor effects of SPION@Au-CS-DOX-FA in a mice tumor model. Changes in the tumor size in representational mice (four groups). (a,b) on day 19 the tumor growth in mice treated with SPION@Au-CS-DOX-FA was reduced significantly $(p<0.01)$ relative to that of the other groups received free DOX, SPION@Au-CS-FA NPs, and PBS. (c) the proliferation index of splenocytes following the induction of tumor lysate, PHA (positive control), and medium (negative control). (d) splenocytes collected from mice treated by SPION@Au-CS-DOX-FA were re-stimulated with tumor lysate. A substantial increase $(p<0.05)$ in IFN- $\ddot{y}$ levels compared with those of other groups and a significant decrease $(p<0.05)$ in IL-4 production was observed in the mice receiving SPION@Au-CS-DOX-FA nanoformulation compared with those given DOX, SPION@Au-CS-FA, and PBS. Results indicate the mean of measurements carried out in triplicate (mean \pm S.D., $\left(^{*} p<0.05 ;{ }^{* *} p<0.01 ;{ }^{* * *} p<0.001\right) ; \mathrm{n}=3$ ).

\section{Conclusions}

The SPION@Au-CS-DOX-FA NPs showed new activity with the release of the pHdependent drug. These NPs act as a platform for DOX drug magnetic vehicle with low cytotoxic effects. Furthermore, in vivo data showed that the tumor development was significantly $(p<0.01)$ inhibited in the mice treated with SPION@Au-CS-DOX-FA NPs compared with those treated with free DOX. We thus conclude that SPION@Au-CS-DOXFA could be developed into a novel formulation which showed remarkable improvement in synergistic therapeutic effects of magnetic drug nanocarriers through their binding with anti-cancer drug DOX for use in clinical treatment of cancer in the future.

Author Contributions: Conceptualization and methodology, S.A.-M., S.A.; formal analysis, F.A., and H.A.-K.; investigation and data curation, S.A.-M., S.A., validation F.A., and H.A.-K.; visualization, S.A., and H.A.-K.; writing—original draft preparation, S.A.-M. and S.A.; writing—review and editing, F.A., and, H.A.-K.; supervision, S.A.-M., S.A.; project administration. All authors have read and agreed to the published version of the manuscript.

Funding: This research received no external funding.

Acknowledgments: The authors extend their appreciation to the Al-Qasim Green University, and University of Misan for their technical support. 
Conflicts of Interest: The authors declare no conflict of interest.

\section{References}

1. Akram, M.; Iqbal, M.; Daniyal, M.; Khan, A.U. Awareness and current knowledge of breast cancer. Biol. Res. 2017, 50, 33. [CrossRef]

2. Ma'mani, L.; Nikzad, S.; Kheiri-Manjili, H.; Al-Musawi, S.; Saeedi, M.; Askarlou, S.; Foroumadi, A.; Shafiee, A. Curcumin-loaded guanidine functionalized PEGylated I3ad mesoporous silica nanoparticles KIT-6: Practical strategy for the breast cancer therapy. Eur. J. Med. Chem. 2014, 83, 646-654. [CrossRef]

3. Senapati, S.; Mahanta, A.K.; Kumar, S.; Maiti, P. Controlled drug delivery vehicles for cancer treatment and their performance. Signal Transduct. Target. Ther. 2018, 3, 7. [CrossRef]

4. Zhao, N.; Woodle, M.C.; Mixson, A.J. Advances in delivery systems for doxorubicin. J. Nanomed. Nanotechnol. 2018,9 , 519. [CrossRef]

5. Rivankar, S. An overview of doxorubicin formulations in cancer therapy. J. Cancer Res. Ther. 2014, 10, 853-858. [CrossRef]

6. Tinoush, B.; Shirdel, I.; Wink, M. Phytochemicals: Potential Lead Molecules for MDR Reversal. Front. Pharmacol. $2020,11,832$. [CrossRef]

7. Costea, T.; Vlad, O.C.; Miclea, L.C.; Ganea, C.; Szöllősi, J.; Mocanu, M.M. Alleviation of Multidrug Resistance by Flavonoid and Non-Flavonoid Compounds in Breast, Lung, Colorectal and Prostate Cancer. Int. J. Mol. Sci. 2020, 21, 401. [CrossRef]

8. Albukhaty, S.; Naderi-Manesh, H.; Tiraihi, T.; Sakhi Jabir, M. Poly-l-lysine-coated superparamagnetic nanoparticles: A novel method for the transfection of pro-BDNF into neural stem cells. Artif. Cells Nanomed. Biotechnol. 2018, 46, S125-S132. [CrossRef]

9. Al-Musawi, S.; Albukhaty, S.; Al-Karagoly, H.; Sulaiman, G.M.; Alwahibi, M.S.; Dewir, Y.H.; Soliman, D.A.; Rizwana, H. Antibacterial Activity of Honey/Chitosan Nanofibers Loaded with Capsaicin and Gold Nanoparticles for Wound Dressing. Molecules 2020, 25, 4770. [CrossRef]

10. Hong, I.K.; Ha, J.H.; Han, S.; Kang, H.; Park, S.N. The Effect of Alkyl Chain Number in Sucrose Surfactant on the Physical Properties of Quercetin-Loaded Deformable Nanoliposome and Its Effect on In Vitro Human Skin Penetration. Nanomaterials 2018, 8, 622. [CrossRef]

11. Antal, I.; Strbak, O.; Khmara, I.; Koneracka, M.; Kubovcikova, M.; Zavisova, V.; Kmetova, M.; Baranovicova, E.; Dobrota, D. MRI Relaxivity Changes of the Magnetic Nanoparticles Induced by Different Amino Acid Coatings. Nanomaterials 2020, 10, 394. [CrossRef] [PubMed]

12. Al-Musawi, S.; Kadhim, M.J.; Hindi, N.K.K. Folated-nanocarrier for paclitaxel drug delivery in leukemia cancer therapy. J. Pharm. Sci. Res. 2018, 10, 749-754.

13. Brero, F.; Albino, M.; Antoccia, A.; Arosio, P.; Avolio, M.; Berardinelli, F.; Bettega, D.; Calzolari, P.; Ciocca, M.; Corti, M.; et al. Hadron Therapy, Magnetic Nanoparticles and Hyperthermia: A Promising Combined Tool for Pancreatic Cancer Treatment. Nanomaterials 2020, 25, 1919. [CrossRef] [PubMed]

14. Nemec, S.; Kralj, S.; Wilhelm, C.; Abou-Hassan, A.; Rols, M.-P.; Kolosnjaj-Tabi, J. Comparison of Iron Oxide Nanoparticles in Photothermia and Magnetic Hyperthermia: Effects of Clustering and Silica Encapsulation on Nanoparticles' Heating Yield. Appl. Sci. 2020, 10, 7322. [CrossRef]

15. Salimi, M.; Sarkar, S.; Hashemi, M.; Saber, R. Treatment of Breast Cancer-Bearing BALB/c Mice with Magnetic Hyperthermia using Dendrimer Functionalized Iron-Oxide Nanoparticles. Nanomaterials 2020, 10, 2310. [CrossRef] [PubMed]

16. Mohammad, F.; Yusof, N.A. Doxorubicin-loaded magnetic gold nanoshells for a combination therapy of hyperthermia and drug delivery. J. Colloid Interface Sci. 2014, 434, 89-97. [CrossRef] [PubMed]

17. Abedin, M.R.; Umapathi, S.; Mahendrakar, H.; Laemthong, T.; Coleman, H.; Muchangi, D.; Santra, S.; Nath, M.; Barua, S. Polymer coated gold-ferric oxide superparamagnetic nanoparticles for theranostic applications. J. Nanobiotechnol. 2018, 16, 80. [CrossRef]

18. Mirnejad, R.; Mofazzal Jahromi, M.A.; Al-Musawi, S.; Pirestani, M.; Fasihi Ramandi, M.; Ahmadi, K.; Rajayi, H.; Mohammad Hassan, Z.; Kamali, M.; Mirnejad, R. Curcumin-loaded Chitosan Tripolyphosphate Nanoparticles as a safe, natural and effective antibiotic inhibits the infection of Staphylococcusaureus and Pseudomonas aeruginosa in vivo. Iran. J. Biotechnol. 2014, 12, 1-8. [CrossRef]

19. Patel, N.R.; Piroyan, A.; Ganta, S.; Morse, A.B.; Candiloro, K.M.; Solon, A.L.; Nack, A.H.; Galati, C.A.; Bora, C.; Maglaty, M.A.; et al. In Vitro and In Vivo evaluation of a novel folate-targeted theranostic nanoemulsion of docetaxel for imaging and improved anti-cancer activity against ovarian cancers. Cancer Biol. Ther. 2018, 19, 554-564. [CrossRef]

20. Yang, C.L.; Chen, J.P.; Wei, K.C.; Chen, J.Y.; Huang, C.W.; Liao, Z.X. Release of Doxorubicin by a Folate-Grafted, Chitosan-Coated Magnetic Nanoparticle. Nanomaterials 2017, 7, 85. [CrossRef]

21. Osial, M.; Rybicka, P.; Pękała, M.; Cichowicz, G.; Cyrański, M.K.; Krysiński, P. Easy Synthesis and Characterization of HolmiumDoped SPIONs. Nanomaterials 2018, 8, 430. [CrossRef] [PubMed]

22. Nassireslami, E.; Ajdarzade, M. Gold Coated Superparamagnetic Iron Oxide Nanoparticles as Effective Nanoparticles to Eradicate Breast Cancer Cells via Photothermal Therapy. Adv. Pharm. Bull. 2018, 8, 201-209. [CrossRef] [PubMed]

23. Al-Kinani, M.A.; Haider, A.J.; Al-Musawi, S. Design, construction and characterization of intelligence polymer coated coreshell nanocarrier for curcumin drug encapsulation and delivery in lung cancer therapy purposes. J. Inorg. Organomet. Polym. Mater. 2020. [CrossRef] 
24. Zhao, J.; Zeng, Y.; Xu, S.; Chen, J.; Shen, G.; Yu, C.; Knipe, D.; Yuan, W.; Peng, J.; Xu, W.; et al. A Viral Deamidase Targets the Helicase Domain of RIG-I to Block RNA-Induced Activation. Cell Host Microbe. 2016, 20, 770-784. [CrossRef]

25. Zucchini, N.; de Sousa, G.; Bailly-Maitre, B.; Gugenheim, J.; Bars, R.; Lemaire, G.; Rahmani, R. Regulation of Bcl-2 and Bcl-xL antiapoptotic protein expression by nuclear receptor PXR in primary cultures of human and rat hepatocytes. Biochim. Biophys. Acta 2005, 1745, 48-58. [CrossRef]

26. Golestani Eimani, B.; Sanati, M.H.; Houshmand, M.; Ataei, M.; Akbarian, F.; Shakhssalim, N. Expression and prognostic significance of bcl-2 and bax in the progression and clinical outcome of transitional bladder cell carcinoma. Cell J. 2014, 15, 356-363.

27. Zhong, Y.; Liao, Y.; Fang, S.; Tam, J.P.; Liu, D.X. Up-regulation of Mcl-1 and Bak by coronavirus infection of human, avian and animal cells modulates apoptosis and viral replication. PLoS ONE 2012, 7, e30191. [CrossRef]

28. Babaei, E.; Sadeghizadeh, M.; Hassan, Z.M.; Feizi, M.A.; Najafi, F.; Hashemi, S.M. Dendrosomal curcumin significantly suppresses cancer cell proliferation in vitro and in vivo. Int. Immunopharmacol. 2012, 12, 226-234. [CrossRef]

29. Shah, S.T.; AYehya, W.; Saad, O.; Simarani, K.; Chowdhury, Z.; AAlhadi, A.; Al-Ani, L.A. Surface Functionalization of Iron Oxide Nanoparticles with Gallic Acid as Potential Antioxidant and Antimicrobial Agents. Nanomaterials 2017, 7, 306. [CrossRef]

30. Al-Kinani, M.A.; Haider, A.J.; Al-Musawi, S. High Uniformity Distribution of Fe@Au Preparation by a Micro-Emulsion Method. IOP Conf. Ser.: Mater. Sci. Eng. 2020, 987, 012013. [CrossRef]

31. Assa, F.; Jafarizadeh-Malmiri, H.; Ajamein, H.; Vaghari, H.; Anarjan, N.; Ahmadi, O.; Berenjian, A. Chitosan magnetic nanoparticles for drug delivery systems. Crit. Rev. Biotechnol. 2017, 37, 492-509. [CrossRef] [PubMed]

32. Angelopoulou, A.; Kolokithas-Ntoukas, A.; Fytas, C.; Avgoustakis, K. Folic Acid-Functionalized, Condensed Magnetic Nanoparticles for Targeted Delivery of Doxorubicin to Tumor Cancer Cells Overexpressing the Folate Receptor. ACS Omega 2019, 4, 22214-22227. [CrossRef] [PubMed]

33. Jabir, M.; Sahib, U.I.; Taqi, Z.; Taha, A.; Sulaiman, G.; Albukhaty, S.; Al-Shammari, A.; Alwahibi, M.; Soliman, D.; Dewir, Y.H.; et al. Linalool-Loaded Glutathione-Modified Gold Nanoparticles Conjugated with CALNN Peptide as Apoptosis Inducer and NF-кB Translocation Inhibitor in SKOV-3 Cell Line. Int. J. Nanomed. 2020, 15, 9025-9047. [CrossRef] [PubMed]

34. Sodipo, B.K.; Aziz, A.A. Optimization of sonochemical method of functionalizing Amino-Silane on superparamagnetic iron oxide nanoparticles using Central Composite Design. Ultrason. Sonochem. 2020, 64, 104856. [CrossRef] [PubMed]

35. Karamipour Sh Sadjadi, M.S.; Farhadyar, N. Fabrication and spectroscopic studies of folic acid-conjugated Fe $\mathrm{O}_{4} @ \mathrm{Au}$ core-shell for targeted drug delivery application. Spectrochim. Acta A Mol. Biomol. Spectrosc. 2015, 148, 146-155. [CrossRef]

36. Al-Musawi, S.; Hadi, A.J.; Hadi, S.J.; Hindi, N.K.K. Preparation and characterization of folated chitosan-magnetic nanocarrier for 5-fluorouracil drug delivery and studying its effect in bladder cancer therapy. J. Glob. Pharma Tech. 2019, 11, 628-637.

37. Zu, Y.; Zhao, Q.; Zhao, X.; Zu, S.; Meng, L. Process optimization for the preparation of oligomycin-loaded folate-conjugated chitosan nanoparticles as a tumor-targeted drug delivery system using a two-level factorial design method. Int. J. Nanomed. 2011, 6, 3429-3441. [CrossRef]

38. Albukhaty, S.; Al-Musawi, S.; Abdul Mahdi, S.; Sulaiman, G.M.; Alwahibi, M.S.; Dewir, Y.H.; Soliman, D.A.; Rizwana, H. Investigation of Dextran-Coated Superparamagnetic Nanoparticles for Targeted Vinblastine Controlled Release, Delivery, Apoptosis Induction, and Gene Expression in Pancreatic Cancer Cells. Molecules 2020, 25, 4721. [CrossRef]

39. Al-Musawi, S.; Albukhaty, S.; Al-Karagoly, H.; Sulaiman, G.M.; Jabir, M. Dextran-coated superparamagnetic nanoparticles modified with folate for targeted drug delivery of camptothecin. Adv. Nat. Sci. Nanosci. Nanotechnol. 2020, 11, 045009. [CrossRef]

40. Al-Awady, M.J.; Balakit, A.A.; Al-Musawi, S.; Alsultani, M.J.; Ahmed Kamil Alabbasi, M. Investigation of anti-MRSA and anti-cancer activity of eco-friendly synthesized silver nanoparticles from palm dates extract. Nano Biomed. Eng. 2019, 11, 157-169. [CrossRef]

41. Vakili-Ghartavol, R.; Momtazi-Borojeni, A.A.; Vakili-Ghartavol, Z.; Aiyelabegan, H.T.; Jaafari, M.R.; Rezayat, S.M.; Arbabi Bidgoli, S. Toxicity assessment of superparamagnetic iron oxide nanoparticles in different tissues. Artif. Cells Nanomed. Biotechnol. 2020, 48, 443-451. [CrossRef] [PubMed]

42. Lizarbe, M.A.; Barrasa, J.I.; Olmo, N.; Gavilanes, F.; Turnay, J. Annexin-phospholipid interactions. Functional implications. Int. J. Mol. Sci. 2013, 14, 2652-2683. [CrossRef] [PubMed]

43. García-Aranda, M.; Pérez-Ruiz, E.; Redondo, M. Bcl-2 Inhibition to Overcome Resistance to Chemo- and Immunotherapy. Int. J. Mol. Sci. 2018, 19, 3950. [CrossRef] [PubMed]

44. González Fernández, C.; Gómez Pastora, J.; Basauri, A.; Fallanza, M.; Bringas, E.; Chalmers, J.J.; Ortiz, I. Continuous-Flow Separation of Magnetic Particles from Biofluids: How Does the Microdevice Geometry Determine the Separation Performance? Sensors 2020, 20, 3030. [CrossRef] [PubMed]

45. Zhuang, J.; Holay, M.; Park, J.H.; Fang, R.H.; Zhang, J.; Zhang, L. Nanoparticle Delivery of Immunostimulatory Agents for Cancer Immunotherapy. Theranostics 2019, 9, 7826-7848. [CrossRef]

46. Albukhaty, S.; Naderi-Manesh, H.; Tiraihi, T. In vitro labeling of neural stem cells with poly-L-lysine coated super paramagnetic nanoparticles for green fluorescent protein transfection. Iran. Biomed. J. 2013, 17, 71-76. [CrossRef]

47. Castro, F.; Cardoso, A.P.; Gonçalves, R.M.; Serre, K.; Oliveira, M.J. Interferon-Gamma at the Crossroads of Tumor Immune Surveillance or Evasion. Front. Immunol. 2018, 9, 847. [CrossRef] 